\title{
Produtos e serviços de informação para negócios no Brasil: características
}

\section{Mônica Erichsen Nassif Borges Natália Guiné de Mello Carvalho}

\section{Resumo}

Informações sobre mercados, companhias, produtos, estatísticas e legislação, denominadas "informações para negócios", são muito pouco exploradas no Brasil, e essa área de estudos encontra-se desorganizada no país. A demanda por produtos e serviços de informação para negócios cresce gradativamente, em função da necessidade das empresas de acompanhar o mercado em constante mudança. O objetivo deste projeto, desenvolvido em nível de iniciação científica, é caracterizar e analisar produtos e serviços de informação sobre mercado existentes no país, identificando organizações públicas e privadas que desenvolvam atividades voltadas para essa área. Os resultados demonstram algumas características dos produtos e serviços identificados no que diz respeito aos tipos de empresas atendidas, ao âmbito de atendimento, a produtos e serviços mais requisitados e seu formato de apresentação, à maneira como o cliente chega até o prestador de serviços, à comercialização e conteúdo dos produtos e serviços e também às fontes de informação utilizadas em sua elaboração.

\section{Palavras-chave}

Informação para negócios; Produtos de informação; Serviços de informação.

\section{INTRODUÇÃO}

A cada dia torna-se mais claro o papel econômico da informação como insumo para o desenvolvimento de produtos, captação de recursos, conhecimento de mercado e sobrevivência de muitas empresas. A capacidade de uma empresa captar e absorver informação correta e de forma ágil determina suas possibilidades de inovar produtos, aumentar a lucratividade e atender ao cliente, sendo competitiva em um mercado altamente instável e ágil.

O Brasil pouco investe em produtos e serviços de informação, e muitas empresas ainda não conseguem perceber como fazem negócios e decidem os seus rumos tendo como insumo a informação. A indústria brasileira, em função disso e de outros aspectos significativos, tem sofrido bastante para acompanhar as contínuas mudanças de uma economia que exige qualidade de produtos, agilidade de processos e que sofre ameaças constantes do mercado.

Para que seja possível acompanhar as transformações atuais, é fundamental conhecer os concorrentes e parceiros, produtos, fornecedores, dados financeiros e econômicos, bem como questões legais. Para isso, é necessário que estejam organizados e disponíveis produtos e serviços de informação que supram as empresas dos dados necessários para acompanhar o mercado.

As empresas necessitam, cada dia mais, de informação disponibilizada com rapidez e precisão, que demonstre o contexto atual do mercado e da economia nacional e internacional. As empresas brasileiras buscam informações sobre fontes de financiamento, processos de produção, controle de qualida- de, gestão organizacional, bem como sobre fornecedores de máquinas e equipamentos, conforme resultado de pesquisa desenvolvida pela Confederação Nacional da Indústria ${ }^{1}$.

Pouco se conhece, no Brasil, sobre "informação para negócios", definida como aquela que diz respeito a mercado, companhias, produtos, estatísticas e legislação. É uma área de conhecimento ainda recente e pouco explorada no país, que precisa ser consolidada em termos de conhecimentos teóricos, de organização de fontes de informação e produtos/serviços de informação. Além disso, é preciso ressaltar que, à medida que se define uma área de estudos, torna-se possível capacitar pessoas para o exercício de atividades inerentes a essa área. Esse aspecto deve ser desenvolvido com urgência, uma vez que o mercado carece de profissionais que dominem especificamente a área de informação para negócios.

A Escola de Biblioteconomia da UFMG, por meio da linha de pesquisa em informação científica e tecnológica, tem investido em ações no sentido de aprofundar-se na área de informação para negócios. Além disso, o Núcleo Especializado em Capacitação de Pessoal em Informação Tecnológica Industrial (Necapiti), desde a sua implantação, tem desenvolvido atividades voltadas para a discussão das questões de informação para a indústria e para negócios, no sentido de iniciar a organização da área no país, capacitar profissionais e criar subsídios para entidades que atuam com informação para a indústria e para empresas. Dentre essas ações, merece destaque o I Seminário de Informação para Indústria e Comércio Exterior, ocorrido em 1993. 
Sendo assim, não parece caber mais discutir o conceito de informação para negócios, visto que muito já foi dito acerca dos limites de atuação e de estudo desta área. Entretanto, Borges e Campello² levantam uma questão conceitual quando afirmam que o termo "informação para negócios" - antes considerado como aquele que substituiria o termo "informação para indústria", por ser mais abrangente - traz, na realidade, uma perspectiva maior no que diz respeito ao nível de agregação de valor à informação como recurso estratégico e gerador de conhecimento organizacional.

Os grandes serviços de informação que compõem hoje a indústria de informação para negócios apresentam-se especializados, como informa a Simba Information, empresa americana que afirma que os maiores faturamentos em termos de informação se deram com corretagem, notícias financeiras e pesquisas de crédito. Outro exemplo é a empresa britânica Reuters, que distribui, em tempo real, cotações, notícias e informações sobre o mercado financeiro. Na mesma escala, competem a Bloomberg e a Dow Jones, que mantêm estruturas mundiais para captação de notícias econômicas (Lopes ${ }^{3}$ ).

No Brasil, destacam-se a empresa paulista Companhia de Informação, que oferece pacotes de notícias voltados para setores específicos da economia, a CMA e a Broadcast, do Grupo Estado. Mas o negócio que mais lucra com a indústria da informação para negócios é voltado para o fornecimento de informações sobre a capacidade de pagamento das empresas. Somente a Serasa e a SCI dividem este mercado com altos índices de faturamento. É importante citar ainda o Investnews, um serviço da Gazeta Mercantil que disponibiliza notícias, balanços, cotações e índices para as empresas ${ }^{3}$.

O modelo de negócios dessas empresas, que consiste em instalar terminais que despejam informações atualizadas e cobrar uma quantia mensal por terminal, encontra-se ameaçado pela Internet. Ela acaba com a necessidade das redes de terminais dedicados, e os provedores de informação disputam o mercado em igualdade de condições. Isso é fundamental, dada a necessidade de economia, confiabilidade e atua- lização de informações para negócios (Doswell $^{4}$. Para Vernon ${ }^{5}$, não importa o formato: o objetivo é sempre fornecer a informação. Como sugere Campbell6: conveniência de uso é a preocupação número um, seguida por fatores como versatilidade, facilidade de manuseio e de uso.

Para a prestação de serviços de informação para negócios, Abell ${ }^{7}$ define uma estratégia básica que consiste, inicialmente, em identificar necessidades, promover meios confiáveis de captação e manipulação dessas informações, bem como promover o acesso à informação, tanto para o staff que planeja, quanto para o operacional.

Segundo Crawshaw ${ }^{8}$, a maior parte do valor agregado da informação está em sua precisão. Outra grande parcela desse valor agregado está na diversificação das possibilidades de formatos de saída (impresso, eletrônico, audiovisual etc.) para o produto/serviço de informação.

Tanto ele como Farkas-Kohn ${ }^{9}$ ressaltam um fator muito importante e provavelmente diferenciador dos serviços de informação para negócios: a comodidade da informação para o usuário. Ambos colocam, como uma das principais fontes de informação e propaganda para os serviços de informação para negócios, os contatos pessoais. Quanto à forma de cobrança pelos produtos/serviços de informação para negócios, sua sugestão é a cobrança por contratos/projetos.

Os serviços de informação voltados para o provimento de empresas e indústrias existentes no Brasil apresentam competência e forte potencial para atuar na área de informação para negócios. Em levantamento realizado por Souza e Borges $^{10}$, o investimento em serviços de maior agregação de valor à informação, tais como extensão e prospecção tecnológica, bem como resposta técnica, possibilita, às instituições provedoras de serviços de informação, expandir sua atuação para a área de negócios. Constatou-se existir um volume significativo de conteúdo informacional relativo a dados estatísticos, mercado, fornecedores, legislação e aspectos de comercialização.

\section{ORGANIZAÇÃO E RESULTADOS DA PESQUISA}

Os resultados desta pesquisa confirmam este potencial, mas demonstram haver outras questões que devem ser consideradas pelos provedores de informação para negócios. A pesquisa foi idealizada com o intuito de levantar as características dos serviços de informação para negócios existentes no Brasil voltados para as questões de mercado, no que diz respeito a público, fontes de informação, estratégias de divulgação e comercialização. Foram enviados 130 questionários para as seguintes categorias de prestadores de serviços de informação para negócios:

- Núcleos de Informação Tecnológica do PADCT/TIB/IBICT em todo o Brasil;

\section{- 27 unidades do Balcão Sebrae;}

- Centros de Assistência à Média e Pequena Indústria (Campi) de cada estado do país;

$$
\begin{aligned}
& \text { - unidades da Rede CNI-Dampi; } \\
& \text { - associações comerciais; } \\
& \text { - institutos de pesquisa; }
\end{aligned}
$$

- unidades da Federação das Indústrias em todos os estados do país;

- consultores independentes e empresas de consultoria;

- centros de informação/documentação de empresas públicas e privadas.

O questionário utilizado na coleta de dados continha perguntas sobre tipos de produtos e serviços de informação para negócios fornecidos pelas unidades de informação consultadas, sobre o conteúdo informacional dos mesmos e forma de comercialização, sobre o formato de apresentação dos produtos e serviços em questão, sobre os principais clientes e as principais fontes de informação consultadas pelos prestadores de serviços de informação para negócios.

Os resultados da tabulação dos dados do questionário demonstram algumas questões que serão apresentadas a seguir. 
Na tabela 1, podemos verificar que os principais clientes das instituições entrevistadas são empresas de pequeno porte (89\%) e microempresas (83\%), seguidas pelo Sebrae (72\%) e órgãos governamentais (70\%).

O âmbito de atendimento (tabela 2) é preferencialmente estadual (43\%), mas verifica-se também o atendimento individual, internacional e por setor industrial.

Os principais serviços oferecidos, demonstrados na tabela 3, são os de consulta rápida (46\%), cursos (26\%) e eventos $(20 \%)$, mas nota-se que a gama de serviços oferecidos pelas instituições é muito variada. Serviços como resposta técnica, serviços de biblioteca, consultoria, elaboração de bases de dados e de publicações específicas apresentam percentuais de resposta variando de $17 \%$ a $11 \%$.

A tabela 4, a seguir, mostra os formatos de apresentação dos produtos/serviços de informação para negócios, onde é notável a preferência pelo relatório impresso (28\%), apesar do oferecimento de formatos alternativos.

A tabela 5, a seguir, mostra como clientes potenciais tomam conhecimento dos produtos/serviços de informação para negócios que vêm sendo oferecidos. Os contatos pessoais são a principal fonte de informação dos clientes (37\%), seguidos pela mala direta (22\%). Entre as respondentes, poucas empresas possuíam páginas na Internet (4\%), e nenhuma fazia anúncios em revistas de grande circulação.

A tabela 6 , a seguir, que trata da forma de comercialização dos produtos/serviços em questão, demonstra que 54\% das empresas optam por convênios ou o fornecimento gratuito (43\%). É importante ressaltar que somente $17 \%$ veiculam produtos em meio eletrônico, e 7\% são vendidos.

A tabela 7, a seguir, diz respeito ao conteúdo informacional dos produtos/serviços de informação para negócios. As informações mais contempladas são sobre empresas (41\%) e inovações tecnológicas (24\%).
TABELA 1

Clientes atendidos (NR = número de respostas)

\begin{tabular}{lcr}
\hline CLIENTES & NR & $\%$ \\
\hline Empresas de grande porte & 26 & $52 \%$ \\
Empresas de médio porte & 36 & $72 \%$ \\
Empresas de pequeno porte & 45 & $89 \%$ \\
Microempresas & 42 & $83 \%$ \\
Todos os tipos citados & 17 & $37 \%$ \\
PADCT & 17 & $33 \%$ \\
CNI & 22 & $43 \%$ \\
Sebrae & 36 & $72 \%$ \\
Senai & 25 & $54 \%$ \\
Associações de classe & 32 & $63 \%$ \\
Empresas de consultoria & 34 & $67 \%$ \\
Órgãos governamentais & 35 & $70 \%$ \\
Institutos de pesquisa & 24 & $48 \%$ \\
Universidades & 34 & $67 \%$ \\
Outros * & 24 & $48 \%$ \\
Todos os citados & 4 & $9 \%$ \\
\end{tabular}

* Outros: pessoas físicas, escolas particulares, associados, empreendedores, setores de produção, público interno.

\section{TABELA 2}

\section{Âmbito de atendimento (NR = número de respostas)}

\begin{tabular}{lrr}
\hline ÂMBITO DE ATENDIMENTO & NR & $\%$ \\
\hline Nacional & 9 & 11 \\
Regional & 6 & 4 \\
Estadual & 31 & 43 \\
Municipal & 25 & 24 \\
Por setor industrial & 15 & 26 \\
Outros* & 4 & 9 \\
Todos os níveis citados & 25 & 54 \\
\hline
\end{tabular}

* Outros: individual, interno, internacional e por setor comercial.

\section{TABELA 3}

\section{Serviços oferecidos (NR $=$ número de respostas)}

\begin{tabular}{|c|c|c|}
\hline SERVIÇO/PRODUTO & NR & $\%$ \\
\hline Consulta rápida & 28 & 46 \\
\hline Resposta técnica & 16 & 17 \\
\hline Serviços de biblioteca & 12 & 17 \\
\hline Consultoria & 10 & 15 \\
\hline Prospecção tecnológica & 3 & 4 \\
\hline Extensão tecnológica & 5 & 7 \\
\hline Consulta a bases de dados & 8 & 13 \\
\hline Diagnósticos & 9 & 11 \\
\hline Estudos de viabilidade & 4 & 7 \\
\hline Análise de mercado & 4 & 4 \\
\hline Pesquisa de mercado & 3 & 7 \\
\hline Boletins & 4 & 7 \\
\hline Cursos & 16 & 26 \\
\hline Eventos & 14 & 20 \\
\hline Montagem de bases de dados & 2 & 4 \\
\hline Guias & 3 & 4 \\
\hline Manuais & 6 & 9 \\
\hline Vídeos & 4 & 7 \\
\hline Outras publicações* & 5 & 11 \\
\hline Outros serviços ${ }^{* *}$ & 9 & 17 \\
\hline Todos os itens citados & 1 & - \\
\hline
\end{tabular}

* Outras publicações: livros, perfis, software, anuários, revistas, informe conjuntural, Bolsa de Negócios, Jornal do Sebrae, cadastro industrial do estado.

** Outros serviços: informações sobre o registro de marcas e patentes, editoração, registro de empresas, projetos de viabilidade econômica, cursos de pós-graduação, integração escola/empresa, desenvolvimento de módulos multimídia, marketing direto, articulação política. 
Na tabela 8, a seguir, temos dados sobre as principais fontes de informação consultadas pelas instituições fornecedoras de produtos/serviços de informação para negócios. Observa-se que 46\% delas utilizam centros de informação/documentação próprios e $30 \%$ utilizam suas próprias bases de dados. As demais fontes de informação receberam percentuais de resposta fragmentados, mas a consulta à determinada fonte de informação não exclui a consulta a várias outras fontes complementares.

\section{CONCLUSÕES A RESPEITO DOS DADOS COLETADOS}

Os serviços de informação detectados através desta pesquisa revelam características que deixam a desejar ao se considerar a velocidade com que os negócios acontecem.

Verifica-se inicialmente, por meio de literatura, que esta é uma área de atuação ainda restrita a empresas já estabelecidas no ramo, detentoras de um grande mercado. Entretanto, observa-se que os serviços/produtos disponibilizados ao mercado brasileiro por tais empresas talvez não atinjam segmentos empresariais carentes de informação.

Apesar de o número de produtos/serviços oferecidos ser grande, aqueles mais disponibilizados são consulta rápida, cursos e eventos. Os conteúdos desses produtos/serviços são, em sua maioria, inovações tecnológicas e informações sobre empresas, verificando-se a presença, em média, de 10\%, de conteúdos relacionados a dados estatísticos, informações sobre finanças, legislação, importação/exportação e sobre mercado. Há, portanto, presença de alguns conteúdos voltados para negócios, mas é importante que as instituições criem uma imagem de provedores de serviços de informação mais especializados por conteúdos, para que obtenham resultados mais efetivos.

\section{TABELA 4}

\section{Forma de resposta (NR = número de respostas)}

\begin{tabular}{lrr}
\hline FORMATOS DE RESPOSTA & NR & $\%$ \\
\hline Relatório impresso & 18 & 28 \\
Material audiovisual & 9 & 9 \\
Por telefone & 17 & 17 \\
Consulta a base de dados & 6 & 9 \\
Reuniões & 16 & 15 \\
Seminários & 13 & 11 \\
Outros* $^{*}$ & 19 & 39 \\
Todas as alternativas citadas & 10 & 22 \\
\hline
\end{tabular}

* Outros: folders e outros impressos, mídia, visitas, feiras/workshops, Internet, diversos.

\section{TABELA 5}

Formas de acesso aos produtos/serviços (NR = número de respostas)

\begin{tabular}{lrr}
\hline FORMAS DE ACESSO & NR & $\%$ \\
\hline Anúncios em revistas/jornais especializados & 15 & 17 \\
Anúncios em jornais de grande circulação & 14 & 15 \\
Anúncios em revistas de grande circulação & - & - \\
Home page & 3 & 4 \\
Mala direta & 14 & 22 \\
Contatos pessoais & 22 & 37 \\
Telemarketing & 1 & 2 \\
Catálogo telefônico & 1 & 2 \\
Catálogo especializado & 4 & 4 \\
Indicação & 12 & 11 \\
Cursos & 6 & 7 \\
Eventos & 12 & 13 \\
Outros* & 9 & 15 \\
Todas as formas citadas & 1 & - \\
\hline
\end{tabular}

* Outros: Balcão Sebrae, visitas, mídia, reuniões, possui clientes fixos, impressos próprios.

TABELA 6

\section{Forma de comercialização dos produtos/serviços (NR = número de respostas)}

\begin{tabular}{lrr}
\hline FORMAS DE COMERCIALIZAÇÃO & NR & $\%$ \\
\hline Assinaturas & 11 & 20 \\
Gratuito & 21 & 43 \\
Por projeto/contrato & 22 & 37 \\
On-line & 8 & 17 \\
Venda & 6 & 7 \\
Convênios & 25 & 54 \\
Contratos & 15 & 26 \\
Outros $^{*}$ & 17 & 37 \\
\hline
\end{tabular}

* Outros: por consulta, locação de vídeos, em eventos do setor atendido, Internet, Balcão Sebrae, taxas de inscrição ou de serviço, ressarcimento de custos.

\section{TABELA 7}

Conteúdo informacional dos produtos/serviços (NR = número de respostas)

\begin{tabular}{lrr}
\hline CONTEÚDO INFORMACIONAL & N.R. & $\%$ \\
\hline Dados estatísticos & 12 & 20 \\
Inovação tecnológica & 14 & 24 \\
Informações sobre mercado & 16 & 13 \\
Informações sobre empresas & 25 & 41 \\
Informações sobre finanças & 2 & 4 \\
Informações sobre legislação & 13 & 11 \\
Informações sobre fornecedores & 11 & 13 \\
Sobre a comercialização de produtos & 5 & 4 \\
Importação/exportação & 3 & 7 \\
Informações sobre política & 3 & 4 \\
Informações sobre economia & 7 & 11 \\
Outros & 9 & 19 \\
Todos os tipos citados & 4 & 9 \\
\hline
\end{tabular}

* Outros: bolsa de negócios, informações sobre eventos do setor atendido, inspeção qualificada, desenvolvimento empresarial, qualidade e produtividade, tecnologias de processamento, perfis individuais de clientes. 
Um aspecto importante a ser ressaltado diz respeito à forma de comercialização dos produtos. As mais utilizadas são os convênios e o fornecimento gratuito de produtos e serviços. Somente $7 \%$ dos respondentes apresentaram a prática de venda de produtos/serviços, verificando-se também baixo percentual de empresas com páginas comerciais na Internet (4\%). Uma das características mais específicas dos serviços de informação para negócios identificada na literatura é a comercialização dos mesmos por meio de vendas e assinaturas, bem como disponibilização de produtos/serviços em meio eletrônico. O resultado desta pesquisa, junto aos provedores de serviços de informação brasileiros ou no país, vem contradizer esta característica, sendo, portanto, uma questão a ser analisada pelas instituições provedoras desse tipo de serviço.

Além disso, os clientes tomam conhecimento dos produtos/serviços através de contatos pessoais, valorizados pela literatura, e mala direta. Não se verificam práticas efetivas do uso de telemarketing, home pages, anúncios em revistas de grande circulação, atividades estas que podem contribuir enormemente para o marketing dos produtos/serviços, bem como para direcionálos a clientes potenciais.

O que se observa, então, é que os produtos/serviços de informação identificados apresentam características conservadoras, seja na forma de abordar o cliente, seja na divulgação. Parece-nos ser necessário criar uma cultura de informação para negócios nas instituições que atualmente são provedoras de produtos/serviços de informação. Para isto, é importante investir na conscientização dessas instituições e, paralelamente, sensibilizar as empresas para o uso efetivo de produtos/serviços desta natureza.

\section{TABELA 8}

Fontes de informação utilizadas na elaboração dos produtos/serviços (NR = número de respostas)

\begin{tabular}{lrr}
\hline FONTES DE INFORMAÇÃO & NR & $\%$ \\
\hline Núcleos de informação tecnológica & 12 & 17 \\
Órgãos governamentais & 5 & 7 \\
Institutos de pesquisa & 6 & 4 \\
Universidades & 4 & 7 \\
Centros de informação/documentação & 27 & 46 \\
Bibliotecas & 6 & 11 \\
Bases de dados de outras instituições & 6 & 7 \\
Base de dados própria & 23 & 30 \\
Livros & 8 & 13 \\
Jornais & 4 & 7 \\
Revistas especializadas & 8 & 7 \\
Consultores/especialistas & 5 & 9 \\
Diagnósticos & 4 & 4 \\
Outros* & 3 & 7 \\
\hline
\end{tabular}

* Outros: base de dados da CNI, Internet.

Outra questão importante diz respeito à necessidade de se conhecerem os profissionais que atuam junto às instituições voltadas para a prestação de serviços/produtos de informação. Isto é fundamental, no sentido de se estabelecer o perfil e detectar as carências de formação desses profissionais.
Há, portanto, questões a serem identificadas e analisadas no que se refere aos serviços/produtos de informação para negócios no Brasil. É necessário ainda que tais serviços/produtos sejam também conhecidos in loco para que possam ser analisados com maior atenção. 

Plenum, 1985.

Information on markets, companies, products, statistics and laws, called Business Information, are not well explored in Brazil and this field is, therefore, lacking in organization. The demand for Business Information products and services is expanding because of the companies growing need of accompanying the market's constant changes. The purpose of this project is to describe and analyze market information products and services existing in Brazil and to identify public and private organizations developing such activities. The results show some characteristics of the products and services that have been identified in regard to the type of client, the area covered by each company, the most requested products and services and the format in which they are provided, the means by which the client reaches the provider the marketing and contents of products and services and the sources of information used.

\section{Keywords}

Business information; Information products; Information services.

\section{REFERÊNCIAS BIBLIOGRÁFICAS}

1. CNI, DAMPI: SENAI, CIET. Demanda por informação tecnológica pelo setor produtivo. Rio de Janeiro, 1996. 64p.

2. BORGES, Mônica E.N., CAMPELLO, Bernadete S. A organização da informação para negócios no Brasil. Perspectivas em Ciência da Informação, v.2, n.2, jul./dez. 1997. p. 149-162.

3. LOPES, Mikhail. Quem paga, quanto, para saber o quê. Exame, n.10, mai. 1997. p. 98-101.

4. DOSWELL, Andrew. Foundations of business information systems. New York:

5. VERNON, K.D.C. Information sources in management and business. 2 ed. London: Butterworths, 1984

6. CAMPBELL, M.J. Business information services: some aspects of structure, organization and problems. 2 ed. London: Clive Bingly, 1981

7. ABELL, Angela. Developing an information business - the HERTIS experience. Bus. Inf. Review, v. 6, n. 3, p. 27-35, jan. 1990.

8. CRASHAW, Sebastian. Competitive intelligene: developing value added information services. Infomediary, v. 5, p. 19-24, 1991

9. FARKAS-KOHN, Irene S. Information as a corporate resource. Information Services \& Use, v. 9, 1989. p. 205-215.

10. SOUZA, Terezinha de F. C. de, BORGES, Mônica E.N. Instituições provedoras de informação tecnológica no Brasil: análise do potencial para atuação com informação para negócios. Ci. Inf., Brasília, v. 25, n. 1, jan./abr. 1996. p. 52-58

11. ABELL, Angela. Providing information for small firms at Business Link Hertfordshire. Bus. Inf. Review, v. 10, n. 2, p. 48-55, oct. 1994. Information in the capital goods industry in Brazil. LUT, 1987. (tese de doutorado).

18. NORTON, Bob. Sources and uses of business information. Aslib Proceedings, v. 44 , n. 4 , p. $165-172$, apr. 1992

19. PAULINO, R.S. Serviços de informação para negócios: a experiência do jornal Gazeta Mercantil. Ci. Inf., Brasília, v. 23, n. 2, p. 217-225, mai/ago 1994

20. TCHOBANOFF, J.B., PRICE, J. Industrial information service managers: expectations of, and support of, the educational process. Library Trends, v. 42 n. 2, p. 249-256, fall 1993.

Artigo aceito para publicação em 25-3-98. informação e as modernas tendências da tecnologia e dos negócios. RAE, São Paulo, v. 34, n. 6, p. 33-45, nov/dez 1994.

13. COHEN, John. Finding information on suppliers of goods and services in the UK. Bus. Inf. Review, v. 8, n. 1, p. $40-48$, jul. 1991

14. HAYTHORNTHWAITE, J. (Ed). The business information maze: essencial guide. London: Aslib, 1990.

15. KERLINGER, F.N. Metodologia da pesquisa em ciências sociais: um tratamento conceitual. São Paulo: EPU/EDUSP, 1980.

16. MONTALLI, K.M.L. Informação para negócios: reflexões. In: SEMINARIO DE INFORMAÇÃO PARA INDÚSTRIA E COMÉRCIO EXTERIOR, 1 E EXPOSIÇÃO DE AGÊNCIAS DE INFORMAÇÃO PARA EMPRESAS, 1 Belo Horizonte, 1993. Anais... Belo Horizonte: Núcleo de Especialização da Escola de Biblioteconomia da UFMG, 1994.

\section{Mônica Erichsen Nassif Borges}

Professora da Escola de Biblioteconomia da UFMG. Mestre em ciência da informação. Especialista em gerência de recursos de informação para a indústria. Coordenadora do Núcleo Especializado em Capacitação de Pessoal em Informação Tecnológica Industrial da Escola de Biblioteconomia da UFMG.

E-mail: mnassif@eb.ufmg.br

\section{Natália Guiné de Mello Carvalho}

Aluna do Curso de Biblioteconomia da Escola de Biblioteconomia da UFMG. Bolsista de iniciação científica pela Fundação de Amparo à Pesquisa do Estado de Minas Gerais (Fapemig).

E-mail: natalia@joinnet.com.br 